\title{
Selvmord i 1998. Utvikling i selvmordsmønstre i 1990-årene
}

Ved Finn Gjertsen

Fra slutten av 1960-årene til slutten av 1980-årene var det en økning i selumord i Norge, mens det deretter har vaert nedgang med utflating de seneste årene. I 1998 var selvmordsraten på samme nivå som i 1980. Offisiell selumordsstatistikk utarbeides på grunnlag av dødsmelding utstedt av lege og annen undersøkelse om de ytre omstendigheter til skader og forgiftninger, herunder resultat fra rettsmedisinsk obduksjon.

I 1998 registrerte Statistisk sentral byrå 548 selvmord i N orge, 399 menn og 149 kvinner. Dette var 160 færre tilfeller enn i 1988 da det hittil høyeste selvmordstallet er registrert (figur 1). Selvmordsraten var 12,4 per 100000 innbyggere i 1998, og raten blant menn var 2,7 ganger høyere enn blant kvinner. Statistikken omfatter personer som på dødstidspunktet var bosatt i N orge, uansett om dødsfallet fant sted i eller utenfor landets grenser. En gjennomgang av statistikkens grunnlag og de prinsipper som ligger bak utarbeidelse av dødsårsaksstatistikk er tidligere gitt i Suicidologi, sammen med en vurdering av statistikkens pålitelighet (G jertsen 2000).

\section{FIGUR 2}

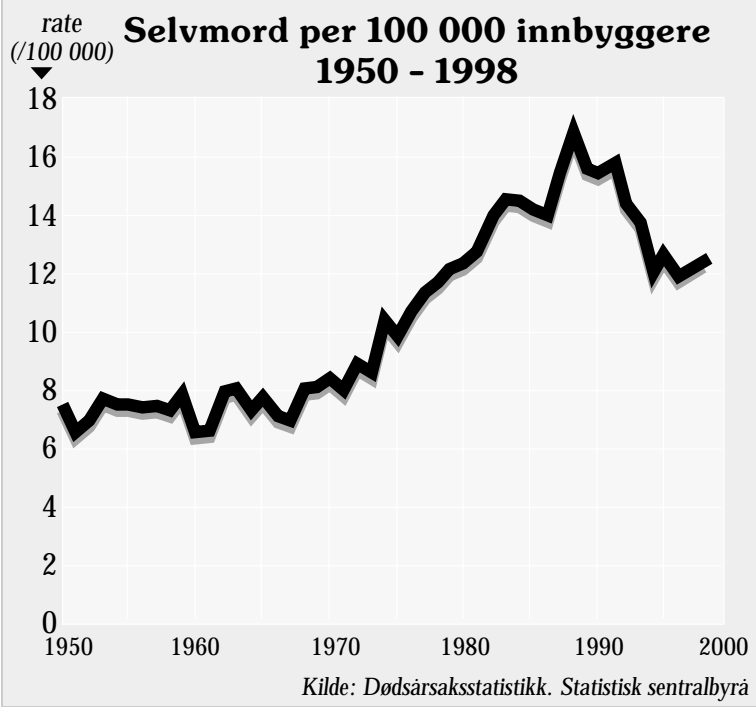

\section{Økning og nedgang}

I 1950- og 1960-årene holdt selvmordsraten seg konstant mellom sju og åtte per 100000 innbyggere, svarende til om lag 250 selvmord per år. Fra slutten av 1960-årene økte selvmordsraten, og i siste halvdel av 1980-årene var raten doblet til 16 per 100000 inn byggere. Det tilsvarer 650 selvmord årlig. Denne fordoblingen gjaldt både menn og kvinner ( $G$ jertsen 1998). Etter 1988 viser den registrerte sel vmordsraten en nedgang og utflating (figur 2).

\section{Metode}

M ønsteret i selvmordsmetoder i 1990-årene er stabilt, og de vanligste selvmordsmetoder er hengning, skytevåpen og forgiftning. Disse metodene ble benyttet i omtrent 80 prosent av alle tilfellene i 1998 (figur 3). Skytevåpen som metode brukes nesten bare av menn. Kun tre prosent av selvmordene blant kvinner skjedde med skytevåpen i 1998 (fire tilfeller, alle under 35 år). Forgiftning er vanligste metode blant kvinner etterfulgt av hengning og drukning. Forgiftning utgjorde 35 prosent av selvmord blant kvinner i 1998 og 22 prosent blant menn. Tre trafikkdødsfall ble registrert som selvmord i 1998, mens 16 døde etter å ha kastet eller lagt seg foran gjenstand $\mathrm{i}$ bevegelse.
FIGUR 1

Selvmord blant menn og kvinner 1975 - 1998

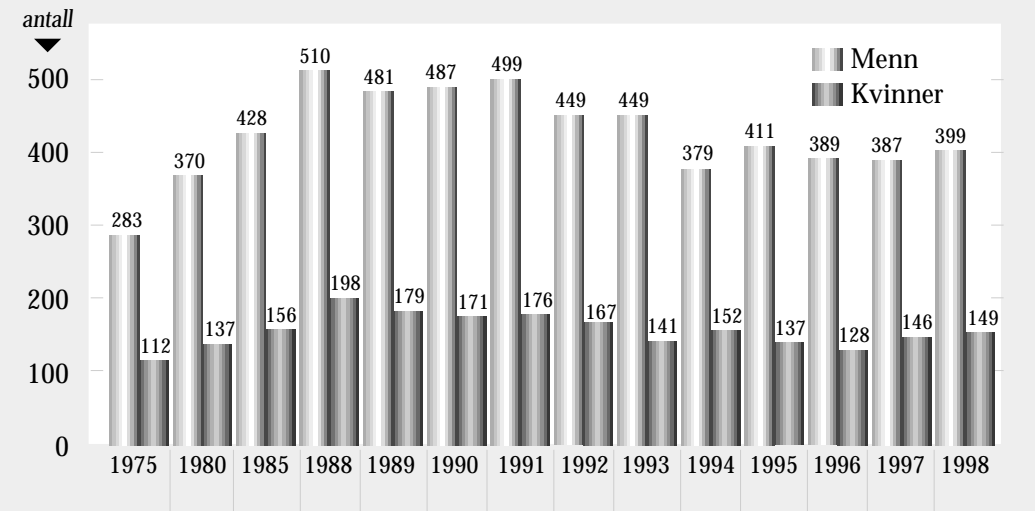

l alt \begin{tabular}{ll|l|l|l|l|l|l|l|l|l|l|l|l|}
395 & 507 & 584 & 708 & 660 & 658 & 675 & 616 & 590 & 531 & 548 & 517 & 533 & 548
\end{tabular}

Kilde: N OS D ødsårsaker. Statistisk sentralbyrå

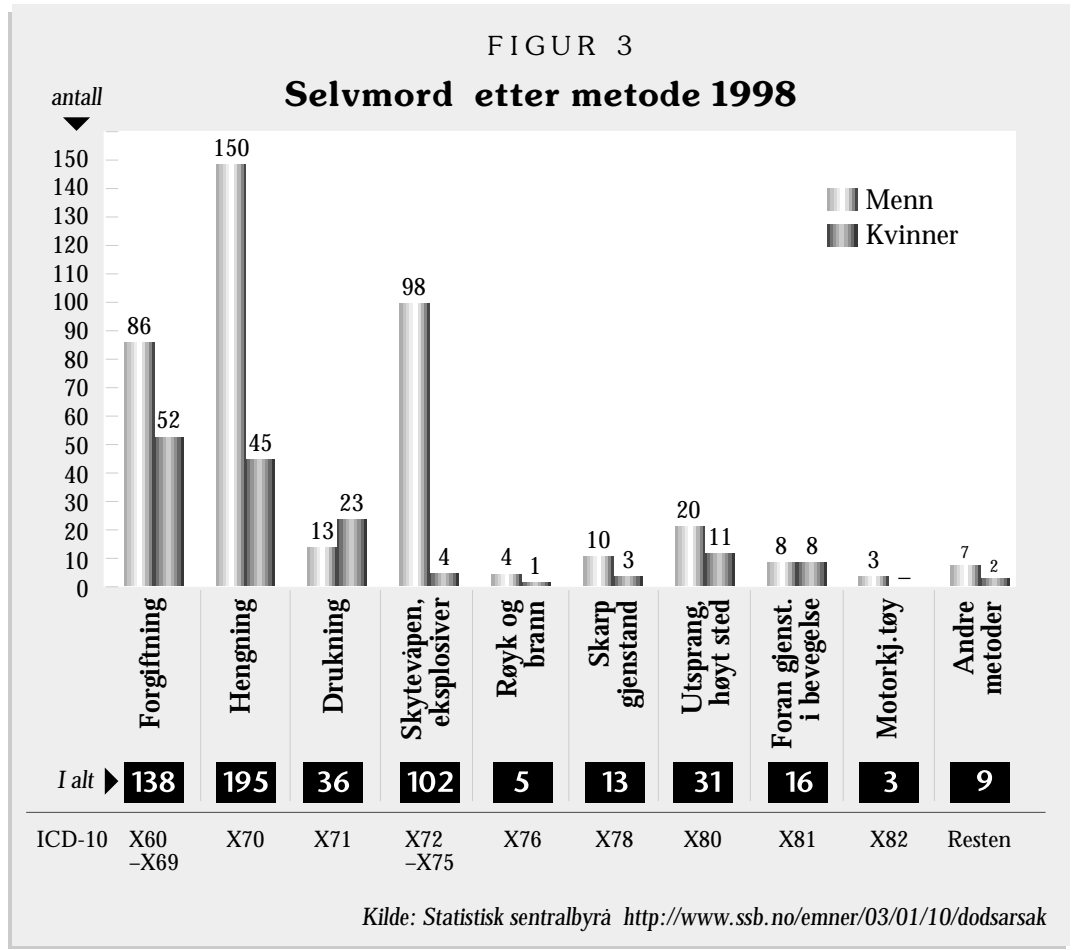


FIGUR 4

Selvmord etter alder 1998

\section{Alder}

Bortimot halvparten av alle selvmord i 1998 (46 prosent) skjedde blant personer i aldersgrupper mellom 35 og 64 år. Det var mer enn dobbelt så mange sel vmord i aldersgrupper under 35 år ( 38 prosent), som blant personer 65 år og over (16 prosent). Imidlertid gir slike andeler et dårlig bilde av utbredelsen av selvmord i de enkelte aldersgrupper, fordi man ikke tar hensyn til størrel sen på befolkningen i de forskjellige aldersgrupper. Blant menn var selvmordsraten per 100000 innbyggere høyest i aldersgruppene 25-34 og 55-64 år i 1998, og i aldersgruppene 65-74 og 45-54 år blant kvinner (figur 4).

Blant barn under 15 år ble det registrert tre selvmord i 1997 og fem i 1998. I 1995 og 1996 var det ni tilfeller i hvert av årene. D et har blitt registrert flere selvmord blant barn i 1990-årene enn i 1970-årene. I perioden 1970-1974 var det i gjennomsnitt to tilfeller årlig.

Blant ungdom og unge menn i alderen 15-24 år var det 62 selvmord i 1996, 58 i 1997 og 67 i 1998. Dette var færre enn hva som ble registrert i begynnelsen av 1990-årene ( 90 i 1991 og 91 i 1992). Figur 5 viser at unge menn i alderen 15-24 år har noe lavere dødelighet i selvmord i siste del av 11-årsperioden 1988-1998, mens nivået blant unge kvinner har vært forholdsvis konstant.

\section{Selvmordssted}

De fleste selvmordshandlinger finner sted i eller ved hjemmet, og i friluft/naturområder (drøye 80 prosent i 1998 hvistilfeller med manglende opplysning holdes utenfor beregningen). 21 selvmord ble gjennomført i sykehus eller andre helse- og pleieinstitusjoner i 1998 (figur 6). A v dette skjedde 13 tilfeller i psykiatriske sykehus og psykiatriske avdelinger i somatiske sykehus. Denne registreringen gjelder skadested, som i en del tilfeller vil være forskjellig fra dødssted. I 1998 fikk M eldesentral en i Statens helsetilsyn rapporter om 33 selvmord blant innlagte pasienter i psykiatrien (Statens helsetilsyn 1999:15). Det fremgår ikke hvor mange av disse som skjedde i permisjon, dvs. utenfor sykehuset.

I 1998 ble det kun registrert 13 dødsfall med uklar ytre årsak til forgiftning og skade, mens tilsvarende tall i 1991, 1995 og 1996 var henholdsvis 23, 18 og 16.

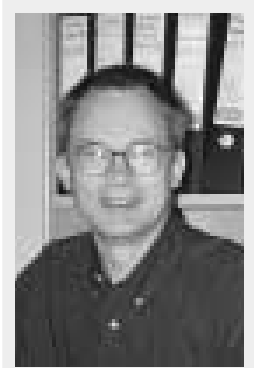

Finn G jertsen er sosiolog (U niversitetet i O slo, 1987) og rådgiver i Statistisk sentralbyrå, Seksjon for hel sestatistikk, og har i flere år hatt faglig ansvar for nasjonal dødsårsaksstatistikk. H an har publisert flere arbeider om selvmord og ulykker. For tiden arbeider han bl.a. med et prosjekt om helseindikatorer og helsestatistikk i Botswana, og en M PH -avhandling om utviklingstendenser i selvmord, datagrunnlag, kvalitet og sammenlikn barhet.

\begin{tabular}{|l|r|r|r|r|r|r|r|r|r|}
\hline \multicolumn{9}{|c|}{ Selvmord etter alder 1998 } \\
\hline & \multicolumn{3}{|c|}{ A ntall } & \multicolumn{3}{c|}{ Prosent } & \multicolumn{3}{c|}{$\begin{array}{c}\text { Per 100 0000 } \\
\text { innbygger }\end{array}$} \\
\hline A Ider & I alt & M & K & I alt & M & K & I alt & M & K \\
\hline $\mathbf{1}$ alt & 548 & 399 & 149 & 100 & 100 & 100 & 12,4 & 18,2 & 6,7 \\
\hline $\mathbf{- 1 4}$ & 5 & 5 & - & 0,9 & 1,3 & - & $*(1,9)$ & $*(3,6)$ & - \\
\hline $\mathbf{1 5 - 2 4}$ & 88 & 67 & 21 & 16,1 & 16,8 & 14,1 & 15,9 & 23,7 & 7,7 \\
\hline $\mathbf{2 5 - 3 4}$ & 116 & 93 & 23 & 21,2 & 23,3 & 15,4 & 16,9 & 26,6 & 6,9 \\
\hline $\mathbf{3 5 - 4 4}$ & 87 & 64 & 23 & 15,9 & 16,0 & 15,4 & 13,7 & 19,7 & 7,4 \\
\hline $\mathbf{4 5 - 5 4}$ & 99 & 68 & 31 & 18,1 & 17,0 & 20,8 & 16,5 & 22,1 & 10,6 \\
\hline $\mathbf{5 5 - 6 4}$ & 65 & 47 & 18 & 11,9 & 11,8 & 12,1 & 16,8 & 24,5 & 9,2 \\
\hline $\mathbf{6 5 - 7 4}$ & 52 & 30 & 22 & 9,5 & 7,5 & 14,8 & 15,0 & 18,7 & 11,8 \\
\hline $\mathbf{7 5 +}$ & 36 & 25 & 11 & 6,6 & 6,3 & 7,4 & 10,5 & 19,8 & 5,1 \\
\hline
\end{tabular}

*: aldersgruppen 10-14 åt. Parentes rundt rater basert på færre enn 10 dødsfall $\quad$ ( $M=$ menn $\mathrm{K}=\mathrm{kvinner}$ )

Kilde: Statistisk sentralbyrå http://www. ssb. no/emner/03/01/10/dodsarsak FIGUR 5

Selvmord blant unge 15-24 år 1988 - 1998

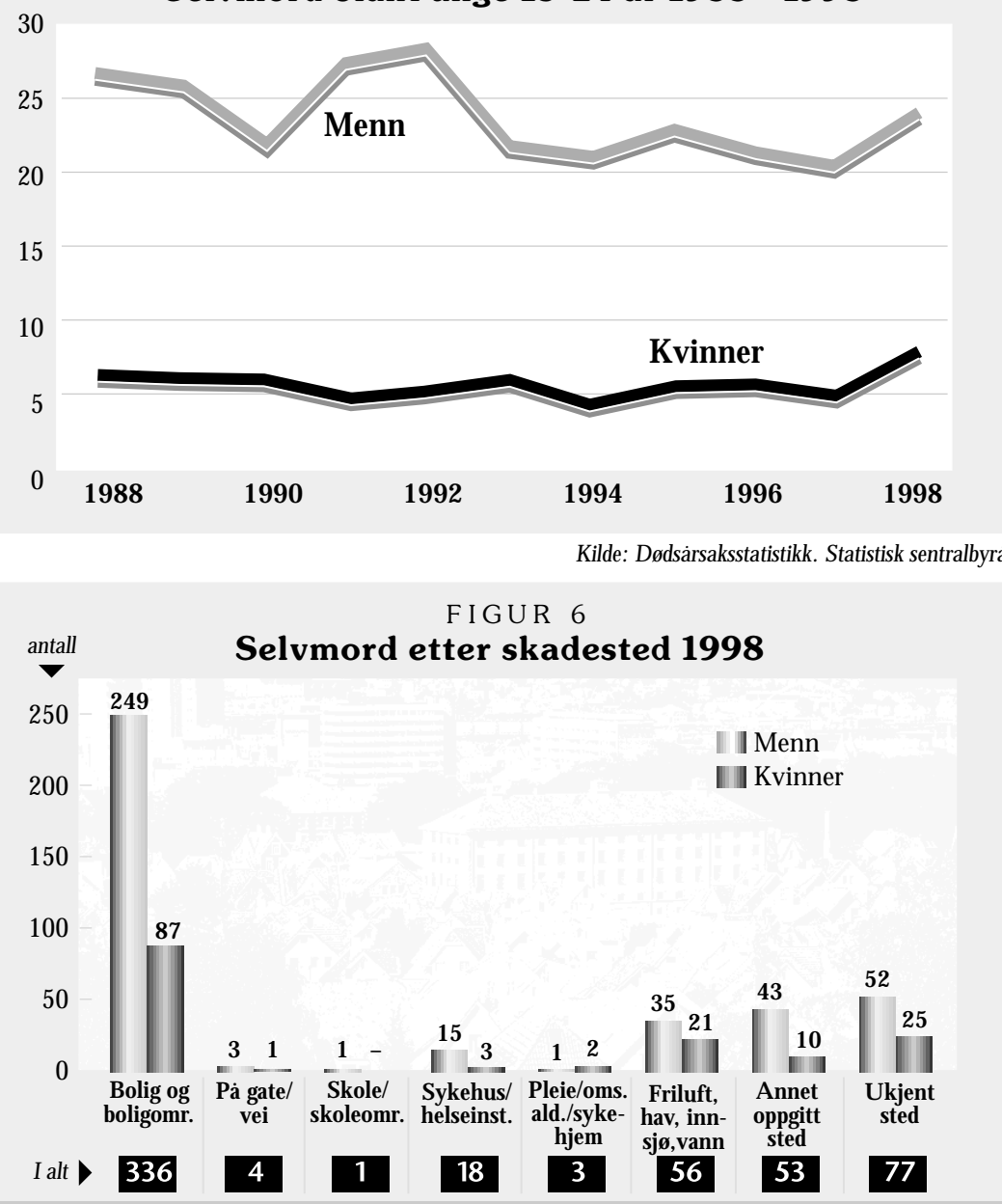

\section{Litteratur}

D agens statistikk. Dødsårsaker, 1998. 30. april 2001. Statistisk sentral byrå

D ødsårsaker 1996. N OS C 591. O sloKongsvinger. Statistisk sentral byrå 2000

D ødsårsaker 1995. N OS C 490. O sloKongsvinger: Statistisk sentral byrå 1998

D ødsårsaker 1991. N OS C 79. 0 sloKongsvinger: Statistisk sentral byrå 1993
Elle-melde-deg-fortelle. Å rsrapport 1998 fra M eldesentralen. Statens helsetilsyn 1999

G jertsen F. Frontkollisjon med fjellvegg, ulykkestilfelle eller selvmord? $0 \mathrm{~m}$ selvmordsstatistikkens pålitelighet. Suicidologi 2000; 5 (2): 18-21.

G jertsen $F$. U tviklingstendenser i selvmord 1950-1995. N ytt i suicidologi 1998; 3 (2) 8-11. 